\title{
Instructional Mash-Up: Promoting Reflective Skill Development in a Virtual Environment
}

Karen Dunlap, Tracey Mac Gowan, and Keith Restine

Texas Woman's University

\begin{abstract}
Classroom management (CM) research suggests prospective teachers customarily view CM skill acquisition as a fundamental component of pedagogical knowledge development (Emmer \& Stough, 2001; Merrett \& Wheldall, 1993). Dissemination of critical concepts has traditionally occurred in face-to-face classrooms supported by school-based field experiences. However, circumstances have fueled student demand for flexible scheduling and convenient online courses (Ellis, 2009; Fink, 2003). Professors are challenged to deliver CM instruction virtually; utilizing multiple tools for online delivery to emulate traditional and educational training experiences. This qualitative study explored emergence of reflective skills in blogs, wikis, and scaffolded assignments in an online CM course.
\end{abstract}

Keywords: classroom management; pedagogy; flexibility; online courses; blogs; wikis; scaffolded assignments 


\section{Instructional Mash-Up: Promoting Reflective Skill Development in a Virtual Environment}

Classroom management (CM) research states preservice teachers conventionally view CM skill acquisition as both a fundamental part of pedagogical knowledge and an absolute core knowledge prerequisite (Emmer \& Stough, 2001; Merrett \& Wheldall, 1993). In their initial efforts to create and maintain safe, orderly, and nurturing environments, beginning educators rely upon CM coursework to provide practices and strategies capable of eliciting appropriate student behaviors.

Traditionally, CM instruction has taken place within collegiate and school-based classrooms where preservice educators are given opportunities to explore, examine, dissect, and implement research-based theories through a variety of university and field-based assignments. The triad formed by university professors, mentor teachers in the field, and preservice educators has conventionally comprised the face-to-face (F2F) connection by which fledgling instructors observe, experiment, and reflect upon nuances of their craft as they become skilled in transferring CM theory to practice.

In today's marketplace, as universities attempt to recruit and retain students, a different pedagogical approach is emerging (Ellis, 2009; Fink, 2003). Professors, who often are not as technologically savvy as the students they teach (Prensky, 2001), are searching for ways to keep pace with the digital dominance while (a) vying for time and acceptance from social networks such as MySpace, Twitter and Facebook, (b) attempting to make lectures more relevant, (c) facing students who exhibit decreased interest in traditional content and instructional approaches, and (d) trading live interactive learners for seemingly invisible students residing in a virtual world (Bonk \& Zhang, 2008, p. 3-4; Ellis, 2009, p. 5). Entering such a dual landscape compels preservice teachers and their instructors to acquire strong foundations in both traditional and new pedagogies. Reconceptualizing the traditional triad to include a fourth dimension, Web 2.0 technologies and associated pedagogies, is worthy of discussion.

\section{Purpose}

This qualitative study examined the integration of Web 2.0 tools (blogs and wikis) into a scaffolded framework of CM techniques and strategies in a virtual context to investigate reflective skill development among graduate students enrolled in an online CM course.

Not every subject...can be taught easily or effectively via online courses....[Such] skills are [those needing] human interaction and modeling of behavior...you would expect they would be learned best in a traditional classroom setting with a 'live' instructor and lots of role playing activities. (Kearsley, n.d., Not for All Content section, para.1-2)

\section{Perspective or Theoretical Framework}

Recently, substantial attention has been given to investigating students' abilities to critically reflect about what they do (Hobgood, Thibault, \& Walbert, n.d.). The road to acquisition of reflective thinking skills, however, is not an automatic one. As Orlich, Harder, Callahan, Trevison, and Brown (2010) assert, "Helping students to reach that goal takes time, knowledge, awareness, and planning on the part of the teacher” (p. 285). Indeed, the press has criticized schools for not preparing students to be reflectively critical thinkers. According to Knudsen, Duff, and Hoffman (1987), “Among the most frequently heard criticisms, are that...graduates...lack awareness of themselves, and their environment... [they] cannot think critically or solve problems in unstructured situations...” (p. 114). This is unfortunate as once 
novice teachers are assigned to their own classroom, they are expected to translate acquired skills into appropriate actions by assuming the same responsibilities as an experienced teacher (Glassford \& Salinitri, 2007). Fink’s Taxonomy of Significant Learning (2003) was selected as the theoretical perspective to undergird this study and to provide an instructional framework for scaffolding acquisition of higher-order reflective thinking skills.

\section{Taxonomy of Significant Learning}

Fink (2003) acknowledged instructional content delivery via the internet is here to stay. While acknowledging the importance of Bloom's (1956) taxonomy, Fink (2003) suggests a new taxonomy that goes beyond Bloom's cognitive hierarchical learning levels. The categories of Fink's learning taxonomy are "relational and interactive" rather than mandated successive levels and address the following categories of learning: foundational knowledge, application, integration, human dimension, caring, and learning how to learn (Fink, 2003, p. 32). Constituent categories are interrelated as "achieving any one kind of learning simultaneously enhances the possibility of achieving the other kinds of learning as well” (Fink, 2003, p. 32). In contrast to Bloom (1956), Fink (2003) moves instruction from teacher-centred to learning-centred by recommending integrated course designs that interconnect learning goals, teaching/learning learning activities, and feedback and assessment (p. 65). Professors are encouraged to create learning goals that expand beyond content; to engage students in learning activities that do not permit them to exist as passive learners; and to deliver frequent, immediate feedback and assessment in a supportive manner (Fink, 2003, p. 95).

Providing multiple opportunities for student engagement, as this taxonomy suggests, establishes a foundation upon which reflective thinking skills may be built. Brain researchers urge instructors to challenge students through an array of higher-order questioning strategies in an effort to strengthen the brain’s pathways (Cardellichio \& Field, 1997). Indeed, Ó Murchú, (2003) acknowledged that instructors who change their role from sage to guide create an atmosphere infused with meaningful learning. To work toward deep learning demands redistribution of both power and control; essentially, a flattening of the traditional hierarchy (Schrum \& Hong, 2002).

\section{Data Sources}

This qualitative study explored whether specific Web 2.0 tools and associated pedagogies, in conjunction with scaffolded course activities provided evidence of reflective skill development among graduate students in an online CM course. The instructor selected blogs and wikis as representative Web 2.0 tools to drive particular types of interactions in the CM course. Specific course activities presented a sequence of skill acquisition and knowledge development.

Potential study participants were post-baccalaureate distance education students seeking initial teacher certification in a graduate teaching program. Participants were required to complete several core education courses, including this CM course. Appropriate Institutional Review Board (IRB) approval was granted to the researchers for this study.

This particular CM course was offered during a summer term. Although the instructor initially questioned whether this course should (or could) be taught online, alternative instructional activities were sought to address the need for observation activities. As the course design unfolded, the instructor made the decision to deliver this CM course $100 \%$ online, with the exception of two optional on-campus meetings (initial orientation and midterm progress 
check). In an effort to utilize Fink's (2003) definition of significant learning in an interactive environment, elements common to traditional CM courses (required readings, lectures targeting $\mathrm{CM}$ theories, etc.) were reconceptualized and redesigned for online course delivery.

Students attended one on-campus F2F orientation meeting at the semester's beginning. A second on-campus F2F meeting was held mid-semester to provide students a venue in which to practice using course required Web 2.0 tools as CM content focus shifted from acquisition of theoretical knowledge to conceptual knowledge application. During this F2F meeting, the instructional designer explained wikis and blogs from both a technical and student perspective and provided information about online help guides. Four assignments were used to generate data for this study: (a) a pre/post blog entry, (b) a wiki page illustrative of collaborative decision making to a reality-based scenario, (c) student generated content residing in the final column of a course matrix, and (d) the reflection section of the course's culminating final paper.

\section{Pre/Post Blog Entry}

Students were taught how to use the blog feature for personal journaling, and blog settings were managed appropriately to insure conversations were visible only to the instructor and student. A YouTube video showing student behaviors and related instructor responses was used as a pre/post appraisal of student CM knowledge. The video, Shane, was initially viewed prior to CM theoretical model exposure and again at the conclusion of the course. Each time, students were asked to reflect upon (a) expressed teacher expectations (b) appropriateness of teacher responses (c) impact of teacher management technique on student misbehaviour, and (d) alignment of the CM techniques shown on the video with personal management strategies. The intent of this collection activity was to determine if students' responses changed after exposure to CM theory and online instruction.

\section{Wikis}

Wikis were used for collaborative assignments. Students were divided into wiki groups based on certification focus and jointly asked to develop solutions based on specific CM models in response to brief scenarios illustrative of targeted student behaviors. A hypothetical classroom of 20 students, Classroom USA, was created by the instructor and the instructional designer using Articulate. Articulate produced an interactive Flash-based format that was placed in the online course shell. This format was indexed for search-ability, allowing students to rapidly hunt and browse for students. Utilizing Articulate's templates, hypothetical students were created with the following information: (a) name, (b) notes from the previous teacher, (c) notations from the previous year's permanent record, and (d) a scenario based upon current behavior patterns.

Students chose Classroom USA scenarios and responded to situations using a particular CM strategy on the wiki. The wiki provided a means by which the researchers could view problem resolution discussions from initial understandings of CM strategies to final determinations of appropriate measures. Students completed three of these assignments throughout the course. Students participating in the study selected one of the three assignments to share with the researchers.

\section{Final Column of Course Matrix}

The four-column course matrix activity afforded students a private space in which to synthesize elements from each CM theory examined in the course. The first three columns focused on the basic tenets of Assertive Discipline, Love and Logic, and Teacher Effectiveness 
Training respectively. Students were to summarize (a) teacher responsibilities, (b) student responsibilities, (c) incentives, (d) interventions, and (e) office referral protocols for the three CM models addressed during the summer course. Upon completion of data entry within each column, students submitted the matrix to the instructor for feedback. Instructor feedback was intended to help students discover connections between their personal beliefs and CM theory. Information placed in the final column reflected the student's personal student management philosophy.

\section{Reflection Section of Final Paper}

Sections from participants' final papers detailing core beliefs contained in their personal CM systems presented a synthesis of ideas. Students were asked to reflect upon (a) connections between self, theory, and real world applications; and (b) perceptions regarding potential success of their own unique CM behavior plan created within the course.

\section{Techniques}

After final grades were posted for the course, students received a request via email inviting participation in this exploratory qualitative study. Attachments to the email included detailed explanation of the study and informed consent procedures. Students agreeing to participate were asked to email the researcher (a) the four targeted assignments stripped of all identifying information, and (b) a statement granting permission to use their work as data.

Thirty-six of 50 students (72\%) in the graduate level CM course agreed to participate. Students submitted the artifacts previously outlined in the Data Sources section of this paper. Data collected within each category were examined initially by a reading of all artifacts. The researchers independently grouped phrases and words from the artifacts into categories to facilitate the coding process. Codes were developed independently and finalized through a process of collaborative negotiation. The instructor of the course frequently communicated with students, exchanging ideas and insights as a form of member checks to support trustworthiness of codes and themes. Codes that emerged from the study included: (a) feelings of selfassurance/confidence, (b) personal belief/theory alignment, and (c) discernment/rationale of ideas.

\section{Results}

Preliminary data from this informal study do appear to offer a window into the reflective nature of preservice teacher CM knowledge development in an online environment.

\section{Blogs}

Initial student postings of the Shane scenario utilized third person almost exclusively as they blamed the instructor in the video clip for using inappropriate CM strategies. Comments such as, "He was just not doing enough to stop it" (Student A, personal communication, initial Shane post, August 2009), or "Didn't that teacher know he was just choosing the wrong CM technique?” (Student B, personal communication, initial Shane post, August 2009) were the norm. While students tended to use third person to describe the teacher in the video, the same students used I in assertions of uncertainty or self-doubt. Qualified statements included such remarks as: "However, I feel unsure about my ability to judge...the correctness of CM" (Student C, personal communication, initial Shane post, August 2009), and "I don’t feel comfortable in my ability to understand who my students are or how they will act...” (Student D, personal communication, initial Shane post, August 2009). 
Shane blog entries following the semester's conclusion strongly suggested CM instruction impacted student understanding of CM strategies. Students moved from general statements about the video incident to definite ideas as to the appropriate problem solution. Researchers documented an increased mention of CM theories as students (a) personalized their responses to the scenario and (b) expressed increased confidence in explaining how they would have handled the situation as the instructor. One blog response stated,

the teacher's techniques were not appropriate to use with Shane [the video's main character] ....In fact, it seems that the teacher worsens the situation by continuing to agitate, belittle, and chastise Shane so that he becomes embarrassed. As a defense mechanism, Shane retaliates by reacting with hostile, angry, and violent behavior... Rather than ask him to talk to me after class. I would also approach him during class in a non-threatening way...later... I would talk to him [Shane] in an oneon-one relationship sphere in order to show personal attention to him. (Student A, personal communication, post Shane blog, August, 2009)

Another student confidently discussed the rationale he or she would use in a similar situation:

I would have solved the situation using a combination of the Discipline with Dignity model and the Teacher Effectiveness Training (T.E.T.) model. I would have recognized that Shane was acting out and realized that there was a reason for his behavior. I would have given him a warning at the first sign of disruptive behavior. If it continued, I would have asked him in private to meet with me after class, after school, or during lunch to discuss the issue. I would remind him of our social contract and explain that his behavior is breaking our agreement. I would then ask Shane to tell me what is going on with him. (Student C, personal communication, post Shane blog, August 2009)

\section{Wikis}

Wikis were chosen as the collaborative setting where students wrote and discussed scenario solutions in a shared space. Initial wiki discussions were little more than textbook descriptions of the targeted CM model. For example, during early discussions of Assertive Discipline, one wiki group member commented, "I was looking at what was written about the discipline plan and I remember the book saying it is not a good idea to write names on the board, but rather to give misbehaving students a verbal warning and keep track on a spreadsheet or attendance sheet as some critics complain that writing students' names on the board may be humiliating..." (Student E, personal communication, EC-4 Wiki, August 2009). To which a colleague responded within the comment section of the Wiki, "We have got to get past 'the book' and develop a plan of action that illustrates how to solve the problem using the principles contained in Assertive Discipline that will work in our particular problem" (Student F, personal communication, EC-4 Wiki, August, 2009).

As knowledge of the CM model became more familiar to students, solutions evolved to reflect specific characteristics of the theory under study. Students were able to discuss teacher responsibilities, student responsibilities, incentives, interventions, and office referral techniques appropriately within the context of their chosen scenario. The history feature of the wiki gave the instructor a window into student understanding of content as they simultaneously applied theory and negotiated meaning. One student explained the nuances of using Assertive Discipline with middle school students: 
Consistency and clear rules and procedures are key elements. If everyone knows what is expected of them, and they all recognize that consequences will be strictly adhered to, then the classroom can run very smoothly. Middle school students understand that their actions have consequences. However, a teacher has to know his/her students; sometimes the consequence can be viewed as desirable to a particular student. For example, some middle school students think it is "cool" to be in trouble due to peer support, so the threat of office visits may not serve as a deterrent.... (Student F, personal communication, 4-8 Wiki, August 2009)

Wiki data indicated students at all certification levels began to think critically about CM beliefs as they discussed (a) whether their crafted solution would work in reality and (b) what role the teacher plays in the solution's eventual success or failure. One student commented to the rest of her wiki group concerning their Teacher Effectiveness Training scenario solution:

This discipline model would work to a degree with middle school students. One of the problem areas with the technique has to do with teacher authority and respect. Yelling curse words or loudly defying the teacher cannot be tolerated in a middle school classroom. It may be true that the student has a deeper issue and just does not know how to communicate it. This is true with all children; every parent knows that there is usually a deeper issue to every outburst. However, the problem with TET is that remaining calm (which is a good strategy), and then talking to the student is not a good strategy when the room is filled with 28 other 13 year olds. They are watching, and in their eyes, the teacher has lost all authority because the teacher let the incident "go.” (Student G, personal communication, 4-8 Wiki, August 2009)

To which a high school wiki participant discussing Teacher Effectiveness Training added:

I think this discipline model could work in the 'real' classroom for high school students. Regardless of age, I have found every student wants to feel like they are being heard. When a student begins to realize their behavior is affecting the teacher ... it is sometimes possible for the student to back down from exhibiting overly aggressive behavior. Also, when a student notices the teacher is not quick to send them to the office or write them up for behavior, I feel a teacher earns a bit more respect from the student. (Student H, personal communication, 8-12 Wiki, August 2009)

\section{Course Matrix}

The four-column course matrix allowed students to begin making connections between various CM principles and their own teaching philosophy. The first three matrix columns required students to identify specific characteristics from targeted CM models: (a) teacher responsibilities, (b) student responsibilities, (c) incentives used, (d) interventions used, and (e) office referral procedures implemented. Information needed to complete the initial three columns could be found in the course text and supplemental materials. The final matrix column addressed the same five characteristics; but, students were asked to analyze information across the first three columns and enter data reflective of their personal CM philosophy. In other words, students were requested to determine how they plan to address CM within their own classrooms.

Comparison of student content from the first column entry to the final submission showed a noticeable change in language. Student language progressed from regurgitating CM 
theory from course materials to actually disaggregating CM tenets and personalizing them. For example, one student initially tried to force Assertive Discipline into alignment with his/her beliefs concerning classroom management. The student stated in the first column of the matrix, “It would be easy for me to use Assertive Discipline in my classroom except I don't think I could ever be that rigid...it seems like the easiest one to enforce, however, so maybe I will try" (Student I, personal communication, Matrix, August 2009).

The instructor questioned the student as to why he/she wanted to practice a form of management that seemed incongruent with their personality and belief system. When articulating his/her personal student management system in the fourth column of the matrix, this same student wrote, "I now see myself much more student-centred. I want my students to take as much responsibility for their own actions as is developmentally appropriate. For that reason, I want to be more of a Teacher Effectiveness teacher...one that sits knee to knee with the student to work out a plan of their own making...” (Student I, personal communication, Matrix, August 2009). The course matrix was, therefore, included in the overall course design to serve as a clearinghouse of sorts where students could reframe and reflect on particular CM elements they felt aligned with their own teaching philosophy. The matrix also benefited students through the provision of a central location to construct, compare, and align their theoretical beliefs throughout the semester.

\section{Final Course Reflections}

Early coding of students' final course reflections revealed the importance of scaffolding various activities throughout the course as key in promoting thoughtfulness and mindful consideration for applying CM theory in a live classroom. Participants validated the research claim that understanding and implementing effective CM techniques was a top priority. Students discussed the important role successful CM played in molding both the classroom environment and their self-perception as competent teachers. In one student's words,

Developing an effective classroom management plan is a necessary and critical step for beginning teachers. I know having routines, rules, and procedures in place will help me in having an orderly classroom which functions smoothly and facilitates student learning. I believe the most effective classroom management plan is one that meets the needs of me, the teacher, the students, and the school.... (Student J, personal communication, Final Reflection, August 2009)

Students' final course reflections cross-referenced different course activities, interactions, and dialogue. As one student stated,

several factors affected the way I think about teaching now: working with [the blog] gave me practice working effectively on a group project from a distance; considering the different management strategies allowed me to picture myself in the classroom using each one; and using the wiki system gave me practice in a brand new form of technology, one that I could see myself using down the road. (Student K, personal communication, Final Reflection, August 2009)

\section{Significance}

Reframing pedagogical style to meet tech-savvy students in their own environment deepened learning for both students and the instructor. 


\section{Students}

The integration of Web 2.0 tools and conventional course assignments provided multiple opportunities for student construction, collaboration, and reflection upon their emerging CM framework. Blogs provided a private place for conversations with the instructor. Within this space, the instructor delivered feedback that challenged students to question their perceptions, to support their statements with definitive evidence, and to reflect upon the alignment of targeted CM tenets with personally held beliefs. Wikis offered opportunities to participate in shared ownership of collective work similar to that practised in grade level settings at school sites. As students wrestled with creating their unique student management plans, matrix entries enabled analysis of CM tenets both within and across models. The combined process equipped students with digital skills and technical knowledge they may utilize long after CM course completion. Active reflection was encouraged while passive inactivity was discouraged.

Throughout the course, students struggled to articulate their own CM beliefs. Initially, students were not poised to write introspective thoughts and ideas; instead, they wrote safe, almost stilted statements they thought would result in a good grade. Statements such as "If a child does not want to learn, you cannot force it...a teacher has to make sure he/she meets each student where they are and encourage them not to act that way in the future," (Student T, personal communication, initial Shane post, June 2009). However, as the semester progressed, students became more comfortable voicing their own ideas and opinions. By interacting, wrestling, analyzing, and reflecting upon theoretical CM models, student-specific, unique behaviour management approaches emerged. By the course's conclusion, students were able to articulate why and how their personal CM system would prove successful in a live classroom. As one student explained,

The study of the various discipline models really opened my eyes to the many ways a teacher can influence his/her classroom. I never thought about how different each classroom could be based on a teacher's personal style and beliefs. I can only assume that each teacher wants to do what they think is best for their students. However, depending on the beliefs and style, a teacher can really affect a student learning experience... I want to be willing to change my plans in order to meet the personal and educational needs of my students.... (Student T, personal communication, Final Reflection, August 2009)

\section{Instructor}

Initially, the instructor viewed delivery of CM content in an online format with skepticism. What transpired for this instructor, however, was creation of a more transparent vantage point from which to peer into students' minds than may traditionally occur in a F2F classroom. Viewing concept emergence, development, and application via writing within the wiki permitted access to student thought processes at a point where constructive feedback could be used to address any misconceptions. Feedback was provided at more points and in a more individualized manner during the conceptualization process than previously possible in F2F courses. Blogs expanded the number of times a student could receive individual attention from the instructor. Contrary to the instructor's initial impression, online CM instruction connected content and students on a deeper level than previously found in traditional F2F courses.

Additionally, blending Web 2.0 tools familiar to digital natives with traditional CM pedagogy, allowed the instructor to function within the digital native landscape. The technologies embraced by digitally savvy students permitted the connection between university 
coursework and classroom environments to be realized. Evidence of reflection was visible in the depth of learning observed as student's personal CM style emerged through the scaffolded assignments and confirmed in their final reflections. As one student indicated,

This course helped solidify my classroom management beliefs. ...I thought about how I would respond to different situations. As a teacher, I must and can model behavior I want my students to exhibit. (Student L, personal communication, Final Reflection, August 2009)

Lessons learned in a traditional CM course flourished online. As Leh, Koubs, and Davis (2005) attest, the web is the place where numerous opportunities exist for students to share ideas and become critically reflective, and for instructors to guide interactively the development of tomorrow's educators. 


\section{References}

Bloom, B. S. (Ed.),(1956). Taxonomy of educational objectives: The classification of educational goals. Handbook 1: Cognitive domain. New York: David McKay Co. Inc.

Bonk, C. J., \& Zhang, K. (2008). Empowering online learning: 100+ ideas for online reading, reflecting, displaying, and doing. San Francisco, CA: Jossey-Bass.

Cardellichio, T., \& Field, W. (1997). Seven strategies that encourage neural branching. Educational Leadership, 54(6), 33-36.

Ellis, K. (2009). Upfront: The digital generation. Edutopia, 5(3), 5.

Emmer, E. T., \& Stough, L. M. (2001). Classroom management: A critical part of educational psychology and teacher education. Educational Psychologist, 36(2), 103-112.

Fink, L. D. (2003). Creating significant learning experiences: An integrated approach to designing college courses. San Francisco, CA: Jossey-Bass.

Glassford, L. A., \& Salinitri, G. (2007). Designing a successful new teacher induction program: An assessment of the Ontario experience, 2003-2006. Canadian Journal of Educational Administration and Policy, 60. Retrieved from http://www.umanitoba.ca/publications/cjeap/articles/glassfordsalinitri.html

Hobgood, B., Thibault, M., \& Walbert, D. (n.d.) Kinetic connections: Bloom's taxonomy in action. University of North Carolina at Chapel Hill. Retreived from http://www.learnnc.org/lp/pages/778

Kearsley, G. (n.d.). Is online learning for everybody? Retrieved from http://home.sprynet.com/ gkearsley/everybody.htm

Knudsen, K., Duff, T., \& Hoffman, E. (1987). Developing critical thinking and effective communication. In L. Kelley \& K. Sanders (Eds.), Developments in business simulation and experiential exercises: Vol. 14. (pp. 114-117). SC: Hilton Head. Retrieved from http://sbaweb.wayne.edu/ absel/bkl/vol14/14bc.pdf

Leh, A., Koubs, B., \& Davis, D. (2005). Twenty-first century learning: Communities, interaction and ubiquitous computing. Educational Media International 42(93), 237-250.

Liaupsiri2. (2007, September 30). Shane classroom management [Video file]. Retrieved from http://www.youtube.com/watch?v=4iBWHC4Cv_A

Merrett, F., \& Wheldall, K. (1993). How do teachers learn to manage classroom behaviour? A study of teachers' opinions about their initial training with special reference to classroom behaviour management. Educational Studies, 19, 91-106.

Ó Murchú, D. (2003, June). Does good practice in e-learning mirror good practice in classrooms? Paper presented at the meeting of IADIS e-Society, Lisbon, Portugal.

Orlich, D., Harder, R, Callahan, R, Trevison, M., \& Brown, A. (2010). Teaching strategies: A guide to effective instruction. Boston, MA: Wadsworth, Cengage Learning.

Prensky, M. (2001). Digital natives, digital immigrants. On the Horizon, 9(5), 1-6. 
Schrum, L., \& Hong, S. (2002). Dimensions and strategies for online success: Voices from experienced educators. Journal for Asynchronous Learning Networks, 6(1), 57-67. Retrieved from http://www.sloan-c.org/publications/jaln/v6n1/pdf/v6n1_schrum.pdf 